\title{
Using high/low WHSV value to uncover the reaction behavior between methane and iron oxide in packed bed for chemical looping hydrogen generation process
}

Tiantian Fu", Yusan Turap ${ }^{\#}$, Iwei Wang, Yidi Wang, Yongming Wu, Wei Wang*

School of Environment, Tsinghua University, Beijing, 100084, China

* corresponding author: solid@tsinghua.edu.cn

\# contributed equally to this work 


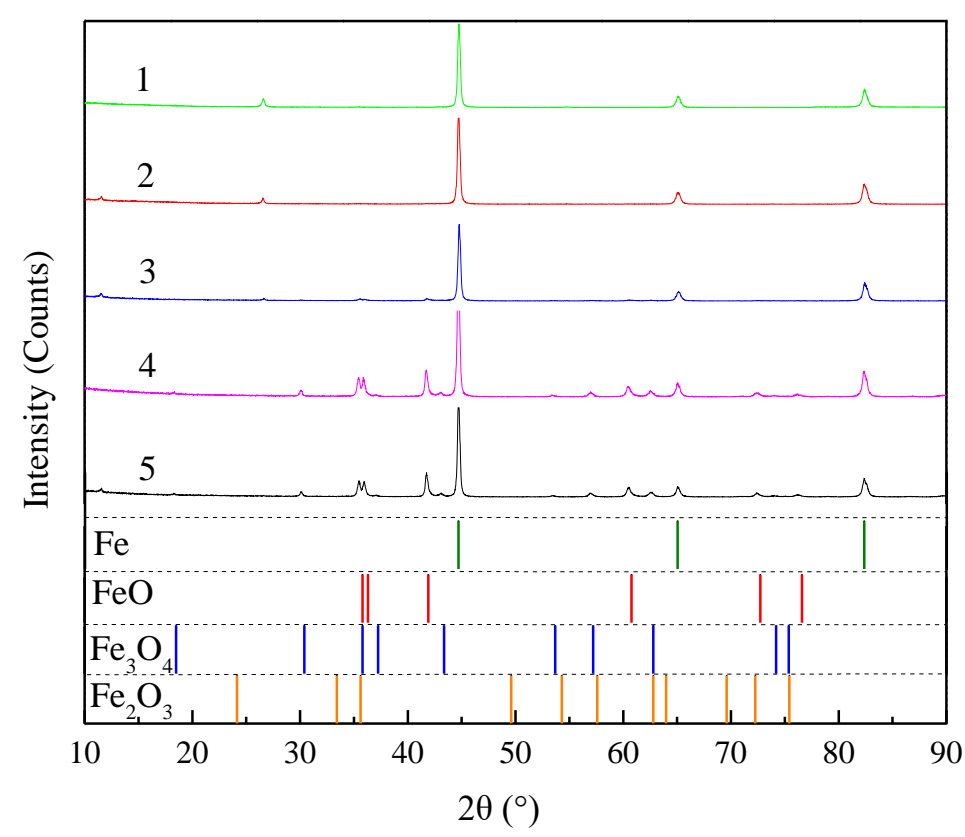

(a)

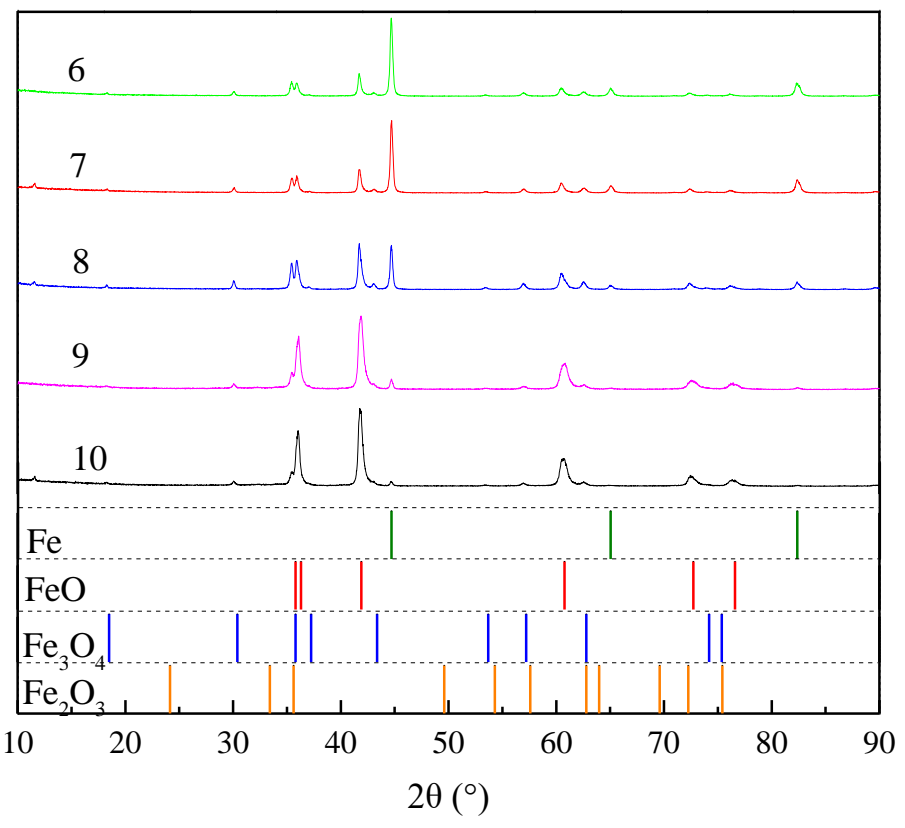

(b)

Figure S1. XRD diagrams of the oxygen carrier in different sublayers after reduction by $50 \% \mathrm{CH}_{4}$ in $\mathrm{N}_{2}$ at $900{ }^{\circ} \mathrm{C}$ for $140 \mathrm{~min}$ (a) sublayer 1 to sublayer 5 and (b) sublayer 6 to sublayer 10

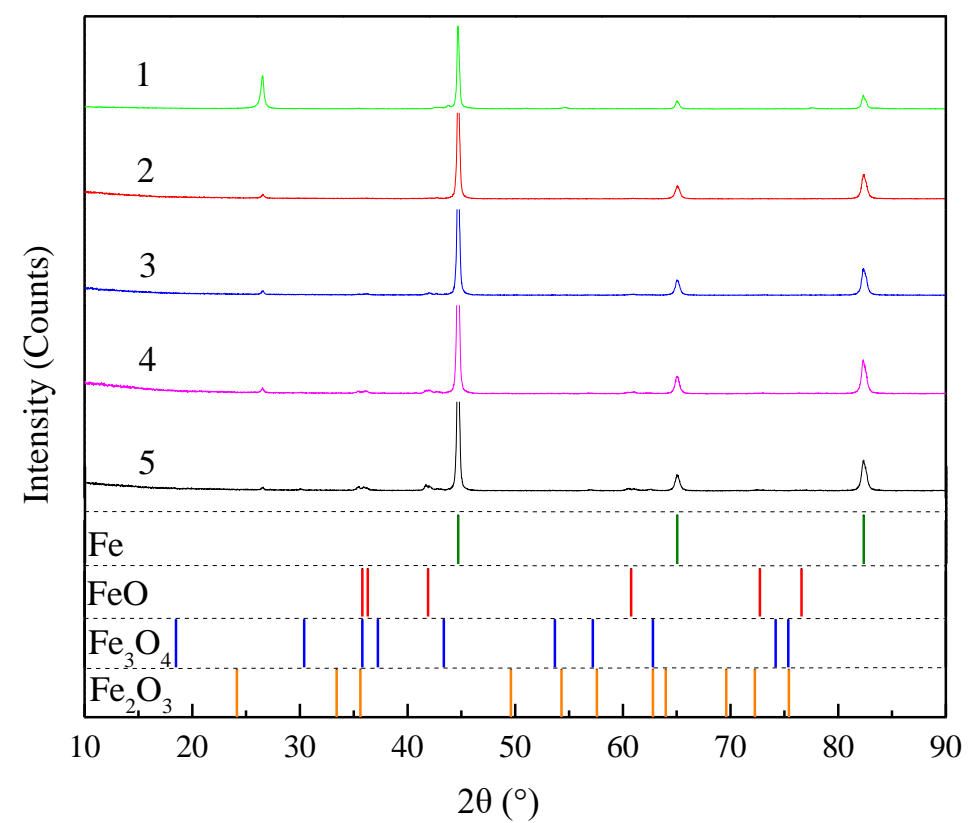

(a)

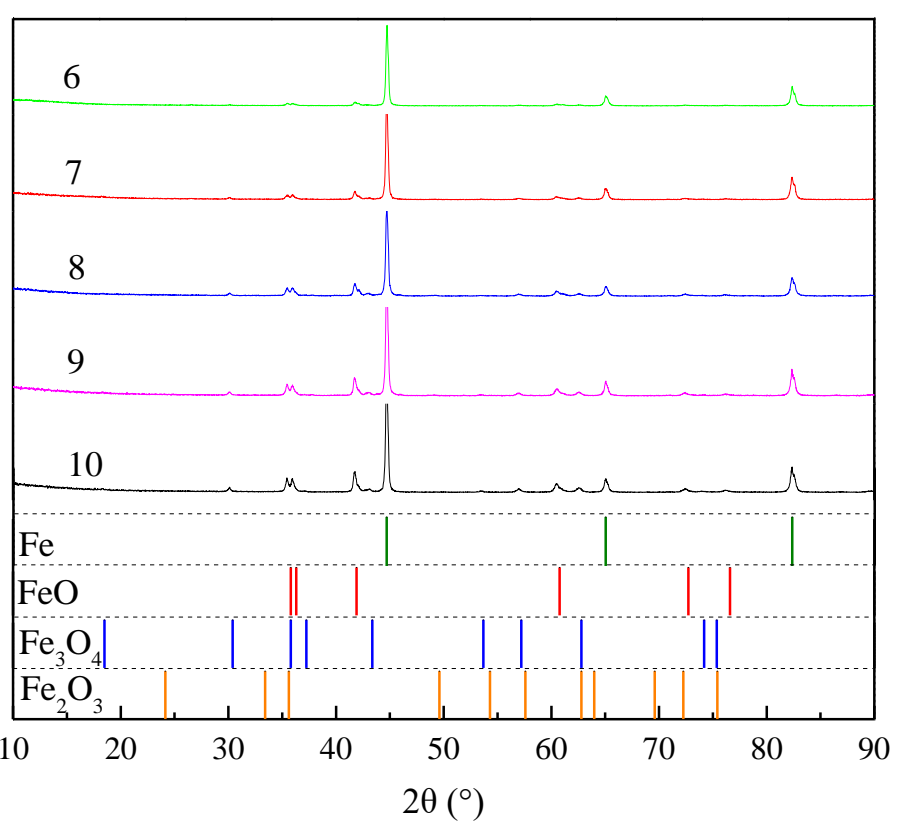

(b)

Figure S2. XRD diagrams of the oxygen carrier in different sublayers after reduction by $50 \% \mathrm{CH}_{4}$ in $\mathrm{N}_{2}$ at $900{ }^{\circ} \mathrm{C}$ for $200 \mathrm{~min}$ (a) sublayer 1 to sublayer 5 and (b) sublayer 6 to sublayer 10 


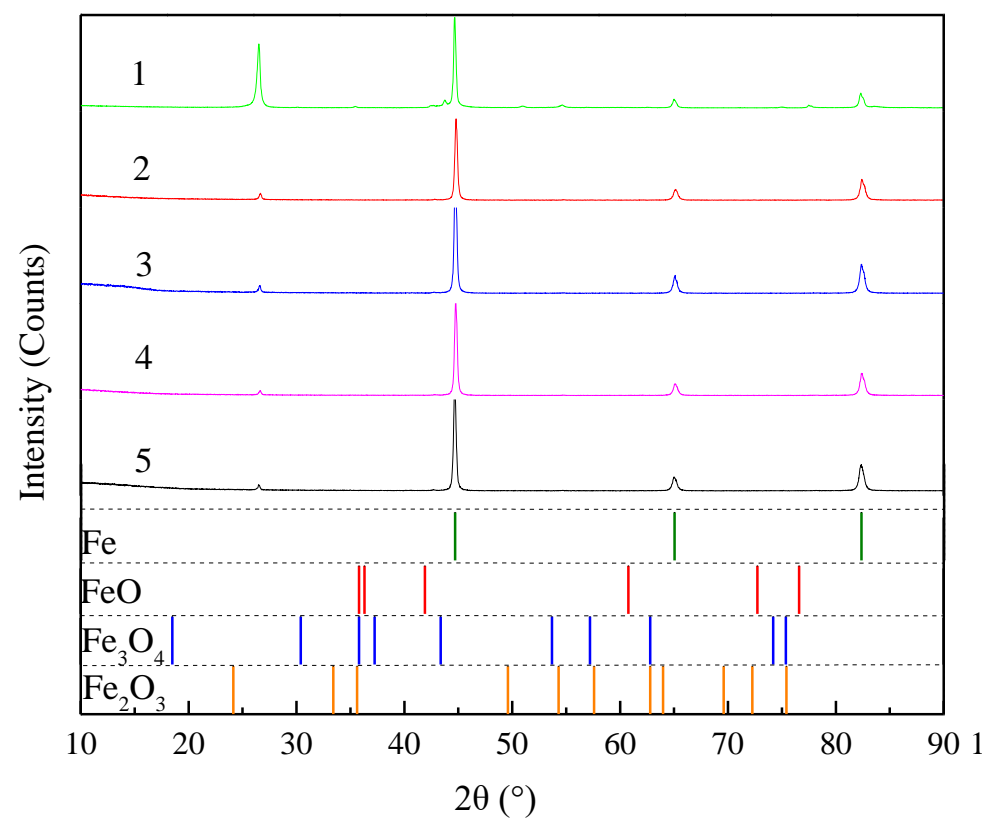

(a)

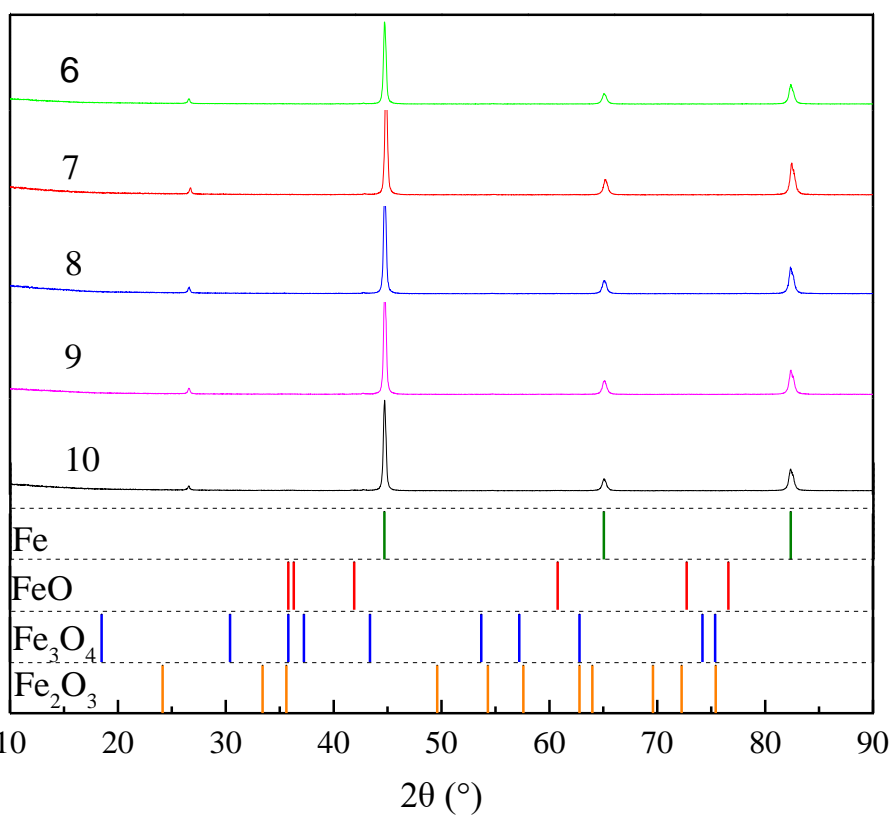

(b)

Figure S3. XRD diagrams of the oxygen carrier in different sublayers after reduction by $50 \% \mathrm{CH}_{4}$ in $\mathrm{N}_{2}$ at $900{ }^{\circ} \mathrm{C}$ for $450 \mathrm{~min}$ (a) sublayer 1 to sublayer 5 and (b) sublayer 6 to sublayer 10 